\title{
Intelligent Drilling Surveillance through Real Time Diagnosis
}

\author{
I. Rey-Fabret ${ }^{1}$, J.F. Nauroy' ${ }^{1}$ O. Vincké', Y. Peysson ${ }^{1}$, I. King ${ }^{1}$, H. Chauvin ${ }^{2}$ and F. Cagnard ${ }^{2}$ \\ 1 Institut français du pétrole, 1 et 4, avenue de Bois-Préau, 92852 Rueil-Malmaison Cedex - France \\ 2 Geoservices, BP 20, 7, rue Isaac-Newton, 93151 Le Blanc-Mesnil - France \\ isabelle.rey-fabret@ifp.fr - j-francois.nauroy@ifp.fr - olivier.vincke@ifp.fr - yannick.peysson@ifp.fr - isabelle.king@ifp.fr \\ herve.chauvin@geosrv.com - florian.cagnard@geosrv.com
}

Résumé — Surveillance intelligente du forage à l'aide du diagnostic temps réel — La surveillance du processus de forage pendant la réalisation d'un puits est fondamentale pour assurer le bon déroulement d'un chantier. À cet effet, des mesures appelées mesures de mud logging, pour la plupart effectuées en cours de forage à l'aide de capteurs installés sur le rig, sont stockées dans des bases de données. Cependant, sans interprétation, elles ne permettent pas de connaître précisément l'état du forage.

Depuis quelques années, l'IFP et Geoservices ont collaboré à un programme de recherche dont l'objectif est de réaliser un système capable d'informer le foreur sur les problèmes qu'il rencontre en cours de forage, en se basant essentiellement sur ces mesures de mud logging.

L'objet de cet article est de présenter ce système, appelé GetSMART, qui à ce jour, aborde la détection en cours de forage des principales vibrations anormales et des dysfonctionnements hydrauliques. Ce système est fondé sur la méthodologie des arbres de diagnostic, dont la richesse est de prendre en compte la connaissance «métier» du foreur pour analyser les signaux de forage et générer des alarmes. Des résultats d'application, déjà obtenus à partir de cas concrets de dysfonctionnements constatés sur chantier, montrent l'intérêt et la pertinence du système GetSMART.

D'autres alarmes seront introduites dans le système dans le futur (i.e. stabilité de paroi).

\begin{abstract}
Intelligent Drilling Surveillance through Real Time Diagnosis - Drilling a well is a complex process which needs to be monitored continuously to ensure that the well will reach its goals. For this purpose mud logging is performed with sensors installed on the rig. However, the direct use of these data is not sufficient to know precisely the state of the drilling process. Processing and interpretation are needed.

IFP and Geoservices have collaborated for many years in a research program dedicated to mud logging data interpretation. A system has been designed to inform the driller about the problems encountered while drilling.

The focus of this paper is to present the system called GetSMART, which aims at the detection while drilling of the main abnormal vibrations and hydraulic malfunctions. The system is based on the diagnosis trees methodology, which allows one to take into account the empirical knowledge of the driller to analyze the signals coming from sensors or physical models and also to generate alarms. Some results obtained on field malfunctions real cases show the interest and the pertinence of the GetSMART system.
\end{abstract}

In the future, others diagnosis trees (i.e. wellbore stability) will be introduced in this system. 


\section{NOMENCLATURE}

BHA: bottom hole assembly

DC: drill collars

FEWD: formation evaluation while drilling

LWD: logging while drilling

ROP: rate of penetration

rpm: rotation per minute

SPP: $\quad$ stand pipe pressure

WOB: weight on bit.

\section{INTRODUCTION}

Monitoring of the drilling process is essential for the safety of the personnel and of the equipment. It is also crucial to optimize drilling performances and reduce costs.

Mud logging has been used since many years. Developed firstly for geological purposes, it uses different types of sensors installed on the rig. The signals provided by these sensors are recorded and stored in databases as a function of time or depth.

First attempts were made in the seventies [1] to try to enhance the utilization of these data by imagining a "smart" way of measuring and detecting the vibrations. An advanced surface data acquisition and processing system was used to produce a so-called "SNAP log". In the eighties, many companies developed high tech sub [2] to measure directly at the top of the drill string the stresses and the vibrations. They used strain gauges to measure tension and torque. These subs are put in place just under the power swivel and the kelly. A high data rate link from these subs to a surface computer allows high frequency drill string vibrations to be measured. Very few commercial applications were developed.

At the same time, IFP has started a research program to understand the sources of abnormal vibrations in the drill string. One aspect of this program was the development of a data acquisition system called TRAFOR including surface and downhole measurement sub.

Rapidly, it appeared that the drill string vibrations are very complex and that using only surface measurements may not be always enough if not enhanced through a model. IFP has developed real time models in which friction laws at the borehole walls and at bit were incorporated $[3,7]$.

The control of hydraulic behavior is also important to secure the drilling operations and avoid malfunction such as bad hole cleaning, plugged nozzle, bit balling, wellbore stability problems, loss of pump efficiency.

The drilling fluid is injected inside the drillpipes to the bit and goes up in the annular to the surface. The mud circulation during drilling has multiple objectives: bit cooling, hole cleaning and maintaining the borehole stability. Injection pressure at surface is known as stand pipe pressure (SPP). This pressure is characteristic of the mud flow through the well and depends on the mud rheology, the drillpipes, the annular geometry, the diameter of the bit nozzles, and so on. The variation of one of these characteristics, but also events coming from the well, create a variation of the mud flow condition and consequently of the SPP.

One of the obstacles in using this stand pipe pressure as unique indicator, is the fact that a change of this pressure can be the result of a variation of mud circulating speed, mud density, or viscosity, etc. The behavior of the stand pipe pressure is not sufficient to distinguish different hydraulic malfunctions.

Last but not least, the basics and the essential of the drilling monitoring for safety purposes relies on the surveillance of pit levels and of mud flow out of the well bore. If this practice is universal since the origin of the modern drilling techniques, it remains a pure empirical observation: only the skills of the person who monitors the operation can allow accurate detection of whether there is an anomaly in the well or not.

In order to improve the whole concept of mud logging surveillance, methods were analyzed from the downstream sector of oil and gas industry and from medical assistance techniques to monitor process in hospital. The new techniques led to the issue of an efficient diagnosis system dedicated to monitoring of oil and gas drilling operations. A real-time intelligent rig-site diagnosis system was developed, which can detect anomalies in the variations in the pit levels, different malfunctions of the hydraulic system in steady state, and abnormal drill string vibrations, taking into account several sensors and model information.

The driller has to react (sometimes quickly) to events when abnormal situations arise. And it is not always obvious to extract only the relevant information from the huge mass of data available from all service companies onboard. In addition, some diagnoses are impossible to do without an appropriate pre-processing of the data. Proposed as the advanced real-time module of the new Geoservices geoNEXT $^{\mathrm{TM}}$ system, a software called GetSMART automatically warns the driller in due time of any abnormal situations. These applications are very cost-efficient compared to the benefits gained, since the crew can make immediate corrective action having a direct impact on the drilling efficiency.

The key to such a system is the implementation on a dedicated workstation, of a special processing software extracting a corrected signal from the raw sensor output. This signal, which takes into account not only the current outputs of the sensors, but also constantly updated typical rig/well responses, will automatically trigger a drilling floor alarm.

The monitoring of the drill string vibrations and the detection of the hydraulic malfunctions are the first topics which were addressed. Research and development programs have been set up through IFP and Geoservices in order to improve the scientific background of the algorithms used by 
this processing software and to enhance the detection capabilities. Current computation availability on board allows more and more sophisticated models to be implemented. The challenge is to stay in line with the necessity to output quickly, without the intervention of a dedicated operator, a reliable and understandable alarm signal that can be used by the drilling crew.

The results of these projects are detailed in the present paper.

\section{ON-SITE INFORMATION}

Two groups of on-site information can be considered: the data available before drilling (a priori data) and the data measured while drilling.

Different acquisition techniques are used while drilling: mud logging (surface sensors), logging while drilling (LWD) and formation evaluation while drilling (FEWD) (down hole sensors integrated in a sub). These data are the main source of information to help the driller.

Some of the measurements done at surface and provided by Geoservices are:

- hook displacement;

- hook load;

- rotation per minute (rpm);

- torque;

- stand pipe pressure (SPP);
- inflow rate;

- outflow rate;

- mud tanks level;

- pump-stroke rate;

- density of the mud in and out;

- mud temperature in and out;

- mud rheology at atmospheric pressure and ambient temperature;

- hydrocarbon and nonhydrocarbon gases liberated from the drilled geological formations;

- cuttings flow.

To this information collected by sensors, we can add computed signals such as:

- total bit depth;

- rate of penetration (ROP);

- weight on bit (WOB);

and many others.

The position of these different sensors and measurements are indicated on Figure 1. Table 1 indicates the sensor types and the usual acquisition frequency. The mud logging companies may also use some additional sensors for complementary information.

Beside the measurement done while drilling, some data (named here a priori data) are available before drilling and are useful to describe the drilling context for wellbore stability detection or other applications. The main a priori data are: well path, drill string composition and drill bit

TABLE 1

Measurements specification

\begin{tabular}{l|l|l|l}
\hline \multicolumn{1}{c|}{ Measurement } & \multicolumn{1}{c|}{ Where? } & Acquisition frequency \\
\hline Stand pipe pressure & Stand pipe manifold & Pressure sensor & 1 to $10 \mathrm{~Hz}$ \\
\hline Mud flow in & $\begin{array}{l}\text { After the pumps } \\
\text { On the pumps }\end{array}$ & $\begin{array}{l}\text { Flowmeter } \\
\text { Stroke pump rate }\end{array}$ & $\begin{array}{l}1 \text { to } 10 \mathrm{~Hz} \\
1 \text { to } 10 \mathrm{~Hz}\end{array}$ \\
\hline Mud density in & $\begin{array}{l}\text { Aspiration mud tank } \\
\text { Indirect }\end{array}$ & $\begin{array}{l}\text { Densimeter } \\
\text { Mud-weight balance }\end{array}$ & $\begin{array}{l}1 \text { to } 10 \mathrm{~Hz} \\
\text { Manual sampling }\end{array}$ \\
\hline Mud density out & Flow line or shaker box & $\begin{array}{l}\text { Densimeter } \\
\text { Indirect }\end{array}$ & $\begin{array}{l}1 \text { to } 10 \mathrm{~Hz} \\
\text { Manual sampling }\end{array}$ \\
\hline Input mud temperature & In the mud tanks & Temperature sensor & 1 to $10 \mathrm{~Hz}$ \\
\hline Output mud temperature & Flow line or shaker box & Temperature sensor & 1 to $10 \mathrm{~Hz}$ \\
\hline Hook Movement & Rig floor & Pulse count & $10 \mathrm{~Hz}$ \\
\hline Hook load & Rig floor & $\begin{array}{l}\text { Pressure on the dead line anchor } \\
\text { or tension on the dead line }\end{array}$ & 10 to $50 \mathrm{~Hz}$ \\
\hline rpm & Rig floor & Number of rotations count & 1 to $10 \mathrm{~Hz}$ \\
\hline Torque & Rig floor & Electrical engine intensity & 10 to $50 \mathrm{~Hz}$ \\
\hline Output mud flow & Flowmeter & $\begin{array}{l}\text { Mass flow of cuttings discarde } \\
\text { at shales shakers }\end{array}$ & 1 to $10 \mathrm{~Hz}$ \\
\hline Cutting flow & Shale shakers & $10 \mathrm{~Hz}$ \\
\hline
\end{tabular}




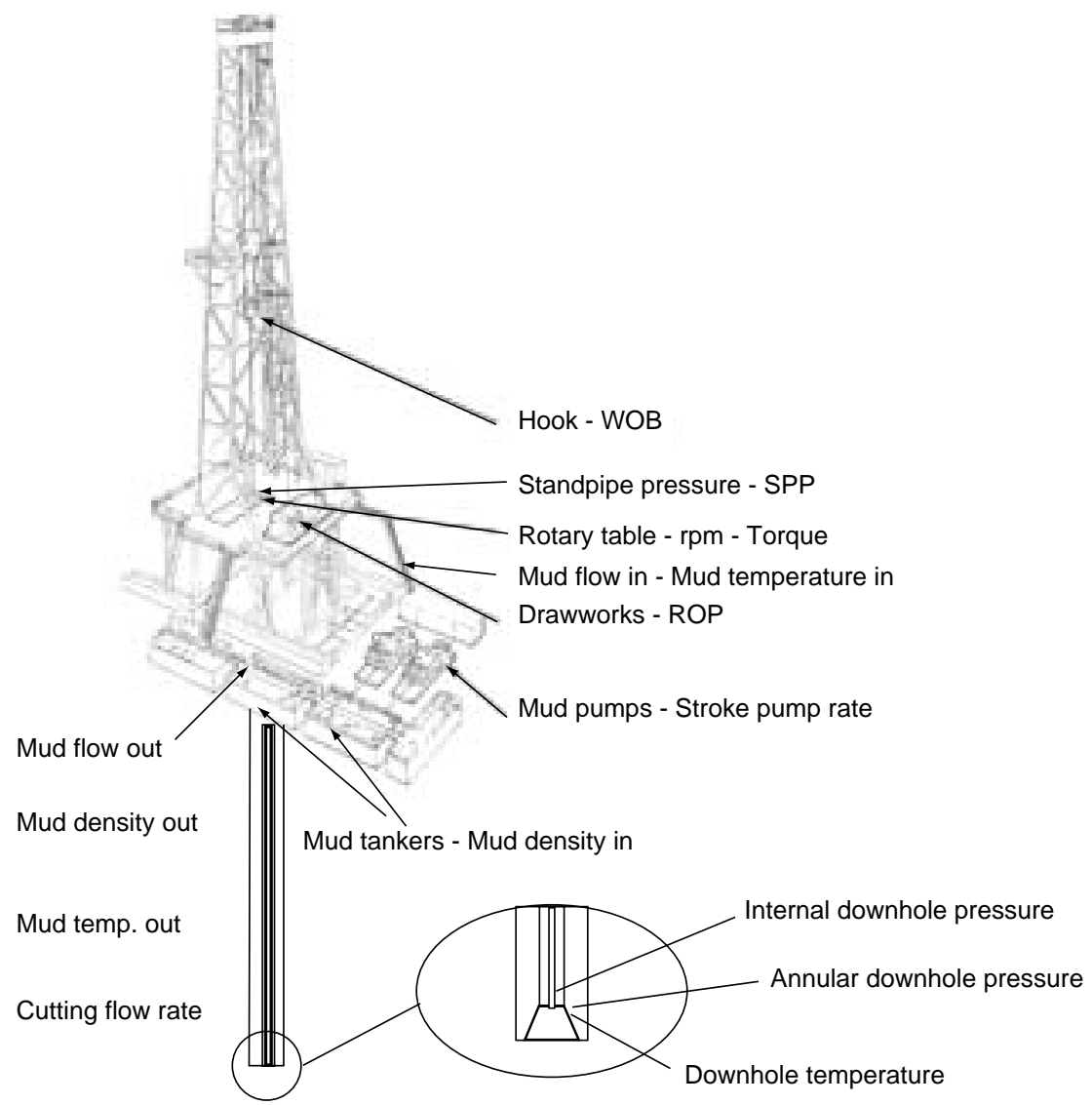

Figure 1

Drilling rig description (after [4]).
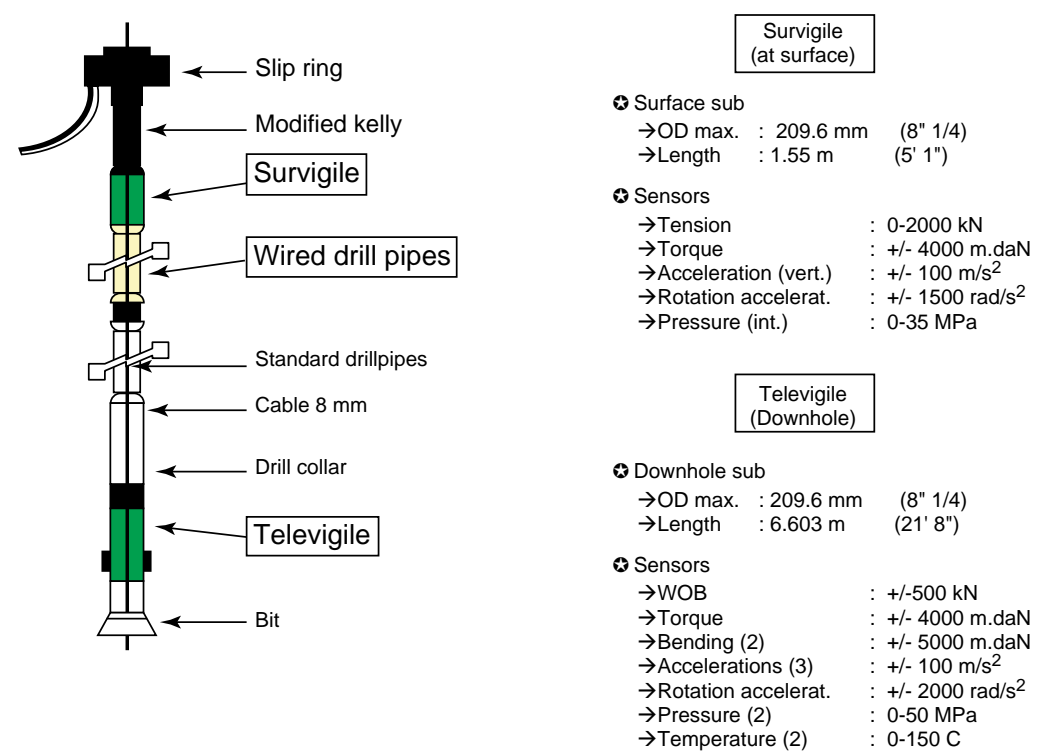

Figure 2

Trafor system. 
characteristics, estimation of in situ stresses mud logging data from previous drilled wells, estimation of pore pressure, fracture and collapse pressure, lithology, unconfined compressive stress (UCS), etc.

The modeling of expected friction coefficient as well as free rotating weight, pick up weight, slack off weight, etc. is also very useful. These data can be determined using well planning software.

These measurements and these a priori data are used as input for the models or diagnosis trees developed by IFP and Geoservices.

Nevertheless, we must keep in mind that all these measurements or all these a priori data may not be available on site simultaneously.

\section{DESCRIPTION OF THE MALFUNCTIONS WHILE DRILLING TAKEN INTO ACCOUNT IN THE GetSMART ALARM SYSTEM}

As stated above, malfunctions of different natures may appear while drilling. In this paper, we focus on the vibrations of the drill string and on the mud hydraulic circuit.

To get a clear understanding of some drilling malfunctions IFP had designed and operated the Trafor system (Fig. 2). It is an MWD system developed for research on drill string dynamic behavior and hydraulic circulation. It measures 15 downhole and 5 surface mechanical parameters. Because Trafor is fitted with an electric link adapted to rotary drilling, it transmits the downhole measurements to the surface in real time with a high rate (1800 measurements per second). All the signals are fully synchronized.

\section{VIBRATIONS}

The Trafor system has shown that the rotary speed at the bit is never constant but has great fluctuations, even when the rpm is set constant at the surface [6]. Sometimes, the bit speed oscillates so much that the bit itself can be at rest for a while, as if it has been plugged into the formation (see Fig. 7 below). Then, the bit can rotate at hundreds of rpm a few milliseconds later. This is known as "stick slip" (Fig. 3). Stick slip is a major malfunction because it induces early fatigue of the equipment that can lead to failures. In addition, a high acceleration level applied on the bit can damage both the bit and the downhole electronics. One can also note an average decrease of ROP during a stick slip phase. The specific frequency is below one hertz $(0.05$ to $0.5 \mathrm{~Hz})$ and is linked with the drill string composition.

Figure 3

Stick slip scheme.

The causes of the stick slip are mainly the high flexibility in the axis of torsion of the drill string and a negative relationship between the torque at bit and the bit rpm: as the instantaneous bit rotation speed increases, the associated torque at bit decreases.

Whirling is a complex motion of some components of the BHA. The BHA does not rotate anymore along its axis but has a complex movement of rotation (Fig. 5).

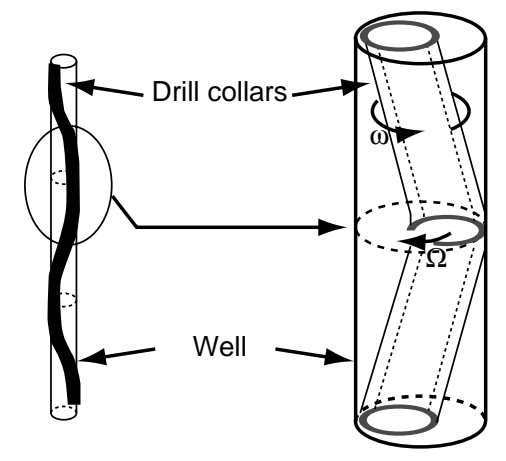

BHA Whril

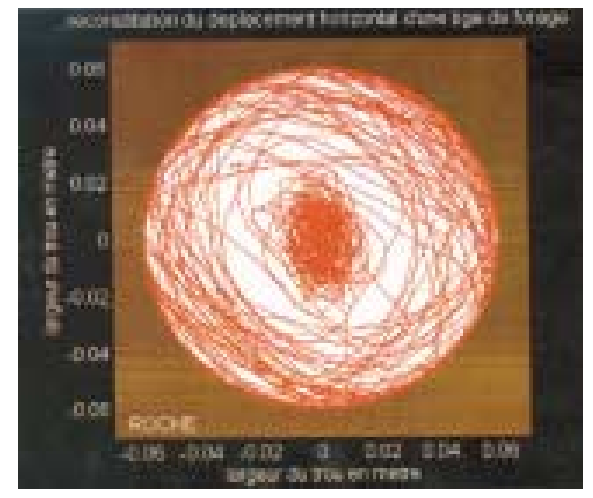

Figure 5

Record of the drill collar position during a BHA whirl.
Figure 4

BHA whirl. 
When whirling occurs the BHA is buckled and takes an S like shape in the well (Fig. 4). The BHA is rotating at a speed $\omega$ but the centerline of its components (DC) rotates itself at a speed $\Omega$. The speed $\omega$ is the instantaneous rotation speed of the drill string. When taking its mean value, it is equal to the $\mathrm{rpm}$. The speed $\Omega$ can be in the same direction as $\omega$ or in opposite side. In the first case, one speaks of forward whirling, in the second one it is backward whirling.

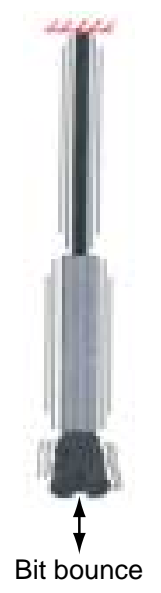

Figure 6

Bit bouncing scheme.
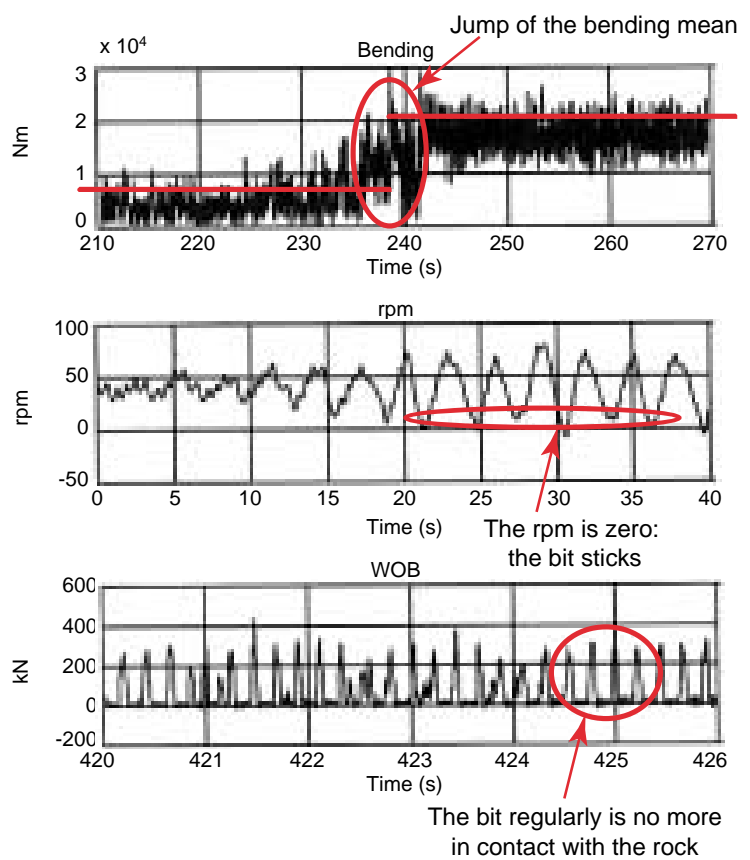

Figure 7

Downhole signatures of abnormal vibrations recorded by the Trafor system.
Whirling induces high bending stresses in the BHA (see Fig. 7 below). A second effect of whirling is the very large shocks against the bore hole walls induced by the complex rotation. These shocks are detrimental to the MWD/LWD systems.

Whirling is difficult to detect [6]. Thus the fatigue can accumulate while drilling and finally a failure of one component of the BHA can occur with a potential costly fishing job.

The bit turning on a lobed pattern at bottom can induce bit bouncing. This phenomenon most often appears with threecones bits. When bit bouncing starts, high variations of weight on bit are recorded. The bit lifts from bottom (WOB becomes null) then shocks against the rock and thus three, six or even nine times per revolution.

If this occurs, the bit can be approximately only $30 \%$ of the time in the situation of drilling. Then, the ROP decreases and important damages on the bit can appear.

\section{HYDRAULIC}

The hydraulic problems that occur while drilling (kick, mud losses, washout, etc.) cause generally important non productive time (NPT) and thus induce an increase of the drilling costs. If corrective actions are not taken early enough these malfunctions can become major accidents such as a blow out.

Some hydraulic malfunctions (mud losses and kick) have been already explored by Geoservices. We have focused our work on detection of the following malfunctions: plugged nozzle, bit balling, washout, bad hole cleaning, bad pump efficiency. Detection of other malfunctions such as borehole stability will be introduced in the improvement of the system. We only consider the cases of rotary or sliding drilling phases, when the mud circulation during drilling is established.

Plugged nozzle: this is due to the cuttings entering the nozzles of the bit when the circulation is stopped, and can induce a decrease of their inside diameter or even plugging. The pressure losses at the bit increase and rate of penetration decreases as the hydraulic impact force and jetting effect become insufficient.

Bit balling: the cuttings stick to the bit surface and cannot be washed away by the mud circulation. At the end the bit is completely covered by stuck cuttings and the bit is no longer in contact with the formation. The main result of bit balling is that the rate of penetration becomes close to zero. In some case, the SPP increases dramatically.

Washout is the name given to a short cut in the hydraulic circuit induced by a hole in a drill pipe. This hole is generally located close to the connection between two pipes, and has many origins such as bad sealing between tool joints or cracks caused by fatigue or corrosion in the pipe body. This 
phenomenon induces a slow decrease of the SPP as the hole diameter increases. In counterpart, the speed of the mud pumps can increase a little. This small increase is difficult to observe and to correlate to a mud flow variation. If the hole in the drill string becomes too large, it may then end by a fishing job induced by the partial loss of the drill string in the well.

Bad hole cleaning: this malfunction is due to a bad cuttings removal in the annular. The cuttings stay in place along the walls, decreasing the area for the mud flow. The torque at surface increases as the pipes grind the cuttings. It is the major cause of the drill string getting stuck or of being unable to run the string back to bottom. Hole cleaning problems represent the major part of the NTP spent on a rig.

The hydraulic mud pump efficiency: the input mud flow rate is the result of the amount of strokes per minute multiplied by the pump liner capacity and by the efficiency of the mud pump.

Here, malfunction can come from a stuck or worn pump valve, from a leak in the pump piston, or from bad filling due to a fluid containing gas. The pump efficiency decreases and the real flow rate is below the nominal pump flow rate. For the same stroke pump rate, the stand pipe pressure and the mud flow rate become smaller than normal. This is a phenomenon which appears gradually.

Well bore stability is another of the major problems encountered while drilling. It is very often the major cause of hole cleaning problems. Some work has been initiated in this domain but has not been implemented yet in the GetSMART system. It should be included in the system in the next coming years.

\section{GetSMART: AN ADVANCED METHOD OF MALFUNCTION DETECTION}

IFP studied an advanced real time method (Fig. 8) of the detection of malfunctions using diagnosis trees. This method analyzes the phenomena and generates alarms for the emergence of the different malfunctions. It allows different kinds of information to be processed, measurements while drilling, a priori information and modeling. The relationship between diagnosis trees and information coming from models is shown in Section 7.

The first step of the work consisted of drilling process analysis to characterize standard working schemes. The second step was to analyze the effects of each problem on the sensors of the rig. Thirdly diagnosis trees were built based on a literature analysis of drilling problem and engineer expertise (Fig. 9) supposing that all the measurements were available to clearly detect the malfunctions. After that, the trees have been improved to allow a decrease in the sensors/measurements number to be supported.

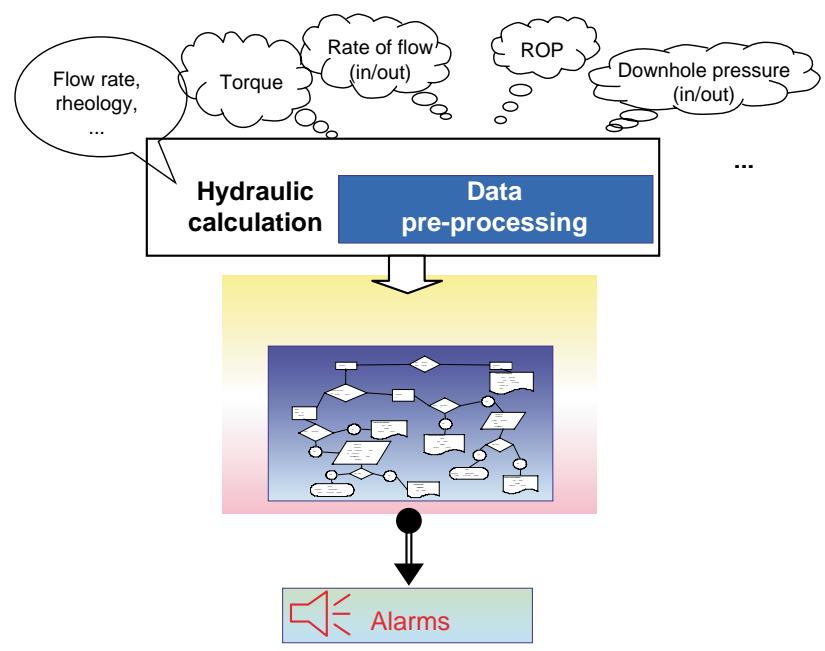

Figure 8

General scheme of the diagnosis trees methodology.

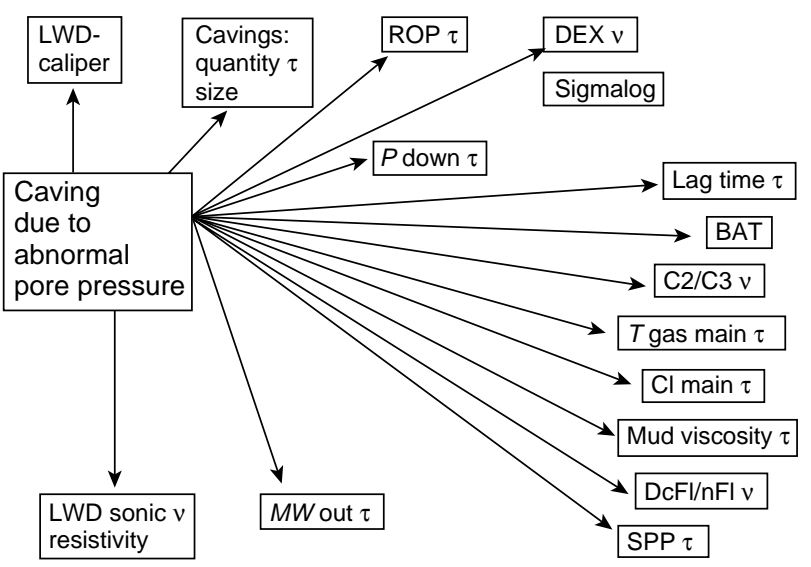

Figure 9

Diagnosis tree example.

\section{ALGORITHMS OF DIAGNOSIS TREES}

The general principle of this method $[9,10]$ is to link each problem with its main symptoms and refutations, within a specific context $[11,12]$. These symptoms and refutations often stem from the operational expertise, and generally express qualitative changes. For example, we know that the malfunction called plugged nozzles involves an increase of the stand pipe pressure. This is a symptom of this malfunction. Inversely, a decrease of SPP with all the other parameters being constant is a refutation of the considered problem.

For each problem, two trees named refutation tree and direct tree have been created. All the problem refutations (noticed $R_{i}$ on figures) are grouped in the first whilst the second contains all its symptoms (noticed $S_{i}$ ). 

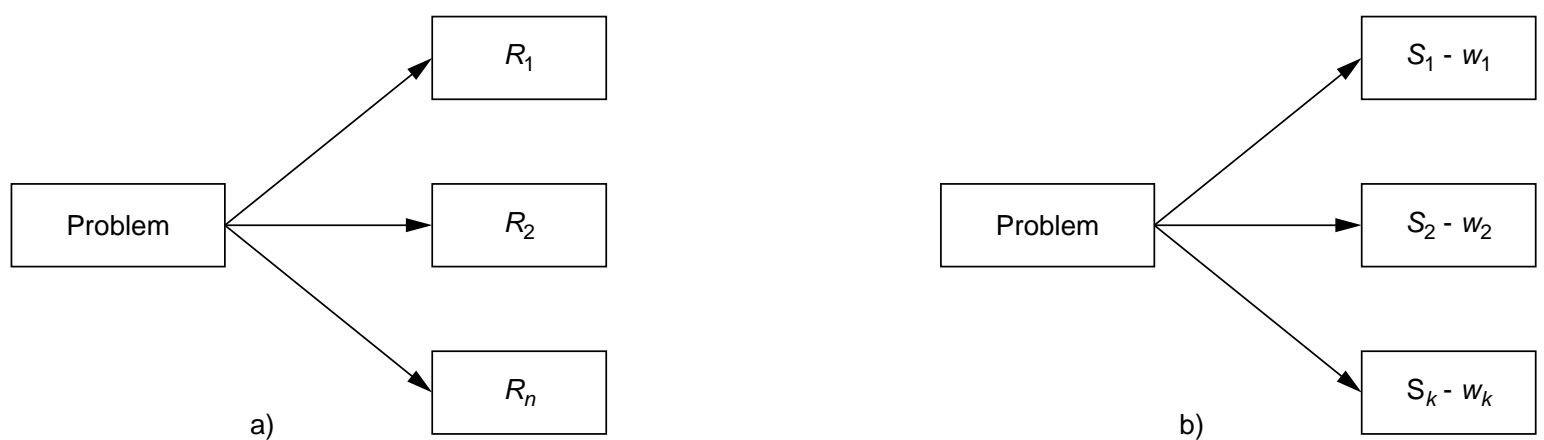

Figure 10

a) refutation tree; b) direct tree.

The drilling is a succession of different contexts: rotary drilling, sliding, drill pipe connection, tripping in/out, etc.

Each of these trees may be limited to a specific context by specific commands, false alarms allowing to be prevented in an inadequate environment: for example the diagnosis "pipe washout" has been defined within the context "circulation", so in other contexts the alarm will not be raised.

To give a reliability estimation of the diagnosis, each symptom contained in a direct tree is weighted by a coefficient (noticed $w_{i}$ ), which quantifies the relative importance of the symptom for the problem, compared to the other ones. For each direct tree, the sum of these coefficients is 100.

The general structures of each kind of tree are given Figures 10a and 10b.

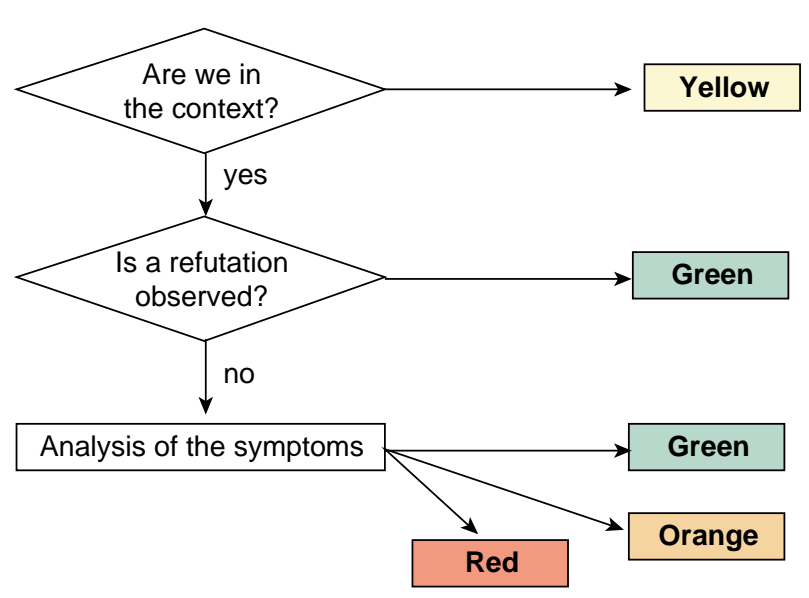

Figure 11

Trees management algorithm.

An algorithm has been written to manage these trees in real time and to propose an associated final diagnosis. This algorithm is composed of four parts:
1 analysis of the context;

2 process of the refutation trees;

3 process of the direct trees if necessary;

4 elaboration of the diagnosis.

For each problem, at each step of time:

- All commands are tested: are we in a context allowing the diagnosis to be detected? If not, the real time indicators turn yellow indicating that the event can not be detected.

- All the refutations are tested. If one or more refutation is verified, the problem is refuted. The algorithm directly goes to the final diagnosis: The considered problem is not present. The real time indicator remains green indicating that we are in a context where the event may be possible but where it is not present.

- At contrary if no refutation is verified, the problem is considered as possible. Then, the algorithm goes to the third step. The different symptoms are tested and the reliability of the diagnosis is estimated by adding the weights of the symptoms which are verified. The considered problem is possible and the corresponding reliability is given to quantify the diagnosis.

Depending on the cumulated percentage of the event occuring, the real time indicator will stay green, pass to orange or go to red.

In practice, the main form of a symptom is a comparison between the behavior of a real time measurement or process and a threshold. For example, if a symptom is defined by the experts as "the SPP increases", its translation in the diagnosis tree is: "the slope of SPP evolution with respect to time is greater than a threshold value".

The tendencies of the signals are often used for the symptoms. They have to represent and to quantify the general behavior of the signal, and not their instantaneous variations with respect to time. Then, a procedure of signal processing is used to extract the general tendency [8] of the considered signal and to quantify it. 
The main difficulty to use this method is to have access to all the information. We can distinguish different cases:

- The signature of the phenomenon is directly available. Only standard signal processing is needed to translate the signal to useful information in the diagnosis trees.

- The signature of the phenomenon is not directly available. A model used as a smart sensor has to be used to generate the useful information to elaborate the diagnosis (for example, a model to estimate the flow rate).

In reality, the diagnosis trees are often a mix of both cases. The signature of a phenomenon is derived from different elements. Some can be deducted from an available measurement, others can be an output of a model, and the association of all of them gives the reliable diagnosis of the phenomenon.

In the next part, we give some examples of phenomena detected by the diagnosis trees method, to illustrate all the previous considerations.

\section{METHODOLOGY: MODELING AND DIAGNOSIS TREES RELATIONSHIP}

In some cases, surface measurements are not sufficient to diagnose the malfunctions. This is the case of stick slip and of bit bouncing.

Sometimes, it is useful to have a software sensor to replace a measurement not always present on-site: it is the case with the estimated mud flow rate derived from the stand pipe pressure.

\section{STICK SLIP}

The stick slip phenomenon induces downhole rpm oscillations at a precise frequency. Therefore, the associated symptoms are the detection of the frequency and the amplitude of the oscillations.

For stick slip the frequency of the phenomenon can be easily detected at surface from the torque measurement. However the amplitude of the stick slip cannot be directly measured from surface sensors. The symptoms and refutations introduced in the diagnosis trees to detect the stick slip are thus not directly linked to the available data. The solution is then to develop a model [5] dedicated to the phenomenon, able to reproduce the part of the downhole signal that contains the signature. A specific model realizes the link between the downhole and the surface. The model takes into account the drill string and the interaction between the drill string and the bit with the walls of the well and its bottom. The model has been reduced to compute in real-time without signal information loss. Stick slip concerns mainly the axis of torsion and thus the torque and the instantaneous rotation speed. Torque measured at surface is used as input in the reduced model. Each time a new measurement is gathered, the model computes a new instantaneous rotation speed at surface. Then a comparison is done between this estimated rpm and the instantaneous rotation speed measured at surface. The model is automatically corrected to minimize the difference between the measured and computed rpm at surface. Another output of the model is the instantaneous rotation speed at bit. As the model is continuously fitted using surface data this process insures that the bit instantaneous rotation speed is correctly estimated.

\section{BIT BOUNCING}

To elaborate the diagnosis trees of this malfunction the problem is more difficult than for stick slip: the signature of this phenomenon is not always available in the surface information so a model has been developed to transfer the pertinent information from downhole to surface.

In this model, the rig plays an important role as it is used to suspend the drill string. Furthermore it is difficult to generate a model of the rig as it involves a complex arrangement of beams and cables; the rig model is then a simplified model reproducing the global behavior of the rig by taking into account only its longitudinal movement.

The other difficulty lies in the interaction between the bit and the formation and the drillstring friction with the borehole. Bit bouncing is generated by a pattern including three or more lobes. Furthermore the bit bounces on the formation and the elasticity of the rock plays an important role in the model.

Taking these unknowns into consideration, a model has been developed to estimate the statistical characteristics of weight on bit from weight on hook and surface rpm measurements.

\section{HYDRAULIC MALFUNCTIONS}

For the detection of hydraulic problems, we have developed a model which estimates the pressure drop created by the drilling mud flow. Mud rheology, well geometry, drill string arrangement and real-time flow rate are needed for the calculation. This model computes the pressure drop along the well without malfunctions and allows calculation of the injection pressure (SPP). This software integrates the temperature and pressure effects on the drilling mud rheology. It determines the pressure in the different parts of the well (inside the drillpipes, annular, drill-bit) from the geometry of the well, the drilling mud characteristics and the well temperature profile.

If the flow rate varies, the estimated stand pipe pressure varies too. Unfortunately, in this case the use of this model as an estimator is insufficient to detect and distinguish the different malfunctions, because some of them (plugged 
nozzles and bit balling, for example) have the same signature on the stand pipe pressure.

This model generates the estimated value of the standpipe pressure. The value of the mudflow rate can also be estimated. For that purpose, the flow rate is adjusted to obtain the measured SPP.

In our diagnosis methodology, all these models (stick slip, bit bouncing and hydraulic calculation) are considered as "smart" sensors and are used as measurements in the diagnosis trees.

\section{REAL CASES OF DETECTION OF ABNORMAL BEHAVIORS DURING DRILLING}

In this part of the paper, we present some real cases of malfunction detection, to illustrate the previous considerations. We propose to detail three situations of abnormal behavior: a situation of stick slip, a bit balling and a drill pipe wash out. Each of them corresponds to one of the cases of use described in the previous paragraph. Through these examples, we show that the access to the pertinent information can be performed through signal processing and/or modeling.

\subsection{Example 1: a Case of Stick Slip}

The stick slip phenomenon induces downhole rpm oscillations at a precise frequency. Therefore, the associated symptoms are the detection of the frequency and the amplitude of the oscillations. As said before, the amplitude of the stick slip is not transmitted to the surface. We are in the case of an unavailable signature of the malfunction at surface. More information must be generated for the symptoms and refutations introduced in the diagnosis trees. One solution is to develop a model dedicated to the phenomenon, able to reproduce the part of the downhole signal which contains the signature. A specific model realizes the link between the downhole and the surface. It takes into account the rotation of the drill string and the contact between the bit and the rock. On the other hand, it doesn't consider the longitudinal and the lateral movements of the drilling system, which are proved non necessary for the stick slip modeling in the case of vertical drilling. Then the model is reduced to be able to compute in real-time but it still contains and represents the stick slip frequencies. Thus this model is only dedicated to the stick slip phenomenon, and is able to estimate the bit rpm at the stick slip frequencies using the rpm and the torque measured at surface. To improve its robustness, a Kalman filter is added to control its time trajectory [5] and to ensure the estimation quality.

In practice, the stick slip model is implemented in the pre-processing part of the alarm system; it is considered as a smart sensor, and generates in real time the useful information for the symptoms and refutations contained in the stick slip diagnosis trees.

As an example, Figure 12 shows the results of the tests performed by the IFP, on-site, in the east of France where all the stick slip events that appear on the log were simulated on purpose by the drillers. This serie of tests has then be used to validate GetSMART in this kind of detection.

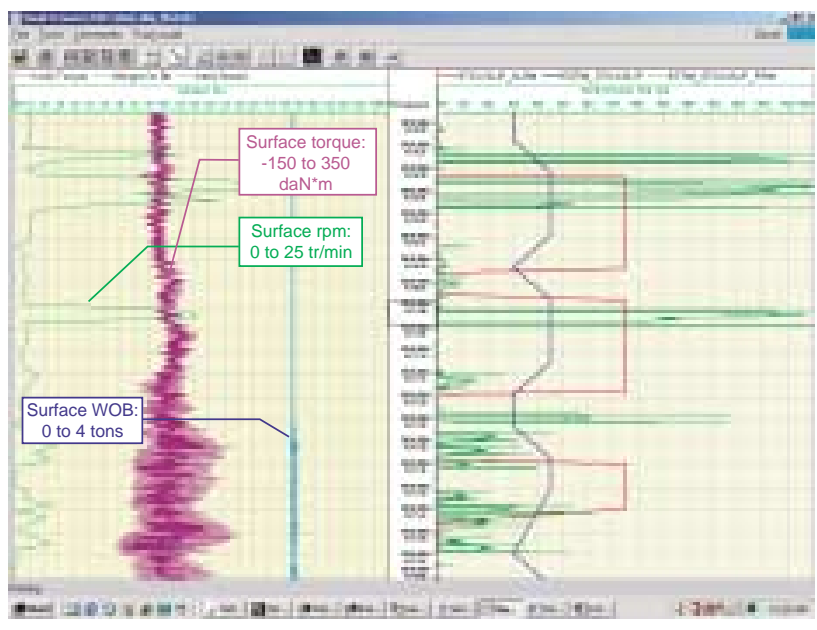

Figure 12

Stick slip simulations and automatic detection on site (east of France)

One can observe on this graph, on the left track:

- surface torque, from -150 to $350 \mathrm{Nm}$;

- surface rpm, from 0 to $25 \mathrm{tr} / \mathrm{min}$;

- surface weight on bit, from 0 to $4 \mathrm{t}$.

The right track displays the calculated parameters:

- Estim_stick slip_rpm, from 0 to 150: this parameter is the so called "smart sensor" estimating the down hole rpm from the torsional spring model designed by IFP.

- Estim_stick slip, from 0 to 20: this is a code scaled from 0 to 6 indicating the level of vibrations. Basically, 4 indicates no stick slip, 5 a slow stick slip and 6 a fast stick slip.

- Stick slip alarm, from 0 to $100 \%$, indicates the probability of the stick slip phenomenon occuring. In this case, the tests were stopped in order to rapidly reach a value of $75 \%$ and more.

The $Y$ axis displays the time, each division corresponding to $5 \mathrm{~s}$.

This example shows:

- that the detection is practically immediate: within one second following increase of the rpm at torque and WOB parameters corresponding to the onset of stick slip, the estimator goes from 4 to 5 or 6 and starts to indicate the abnormal event; 
- the alarm needs a $5 \mathrm{~s}$ delay to confirm the diagnosis and also at least $5 \mathrm{~s}$ (10 in most of the cases displayed here) to be reset to zero.

Obviously, this first version of stick slip indication in real time does not take into account the frictions due to high deviations. However, it is the first way of efficiently trying to "fight" against the worst enemy of PDC bits.

\subsection{Example 2: a Case of Bit Balling}

To illustrate how accurately the diagnosis system works, an example is described in this paragraph. The data acquisition was performed by IFP in a vertical drilling at a depth of $1500 \mathrm{~m}$. Figure 13 is a screen printing of the system. Figure 12 shows data and diagnosis. The system was not monitoring the well in real time firstly, it is important to note

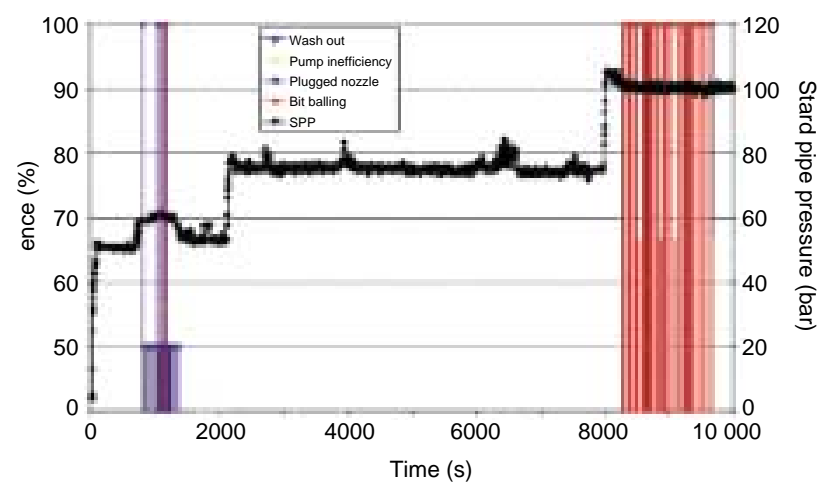

Figure 13

Field test of the system. on the graph that pipe connections occurred at 2000 and $8000 \mathrm{~s}$. The black curve gives the stand pipe pressure evolution. The likelihood of the different malfunctions is shown in color. We see clearly that the unexpected increase of the SPP at $8000 \mathrm{~s}$ is due to a problem of bit balling after tripping in, this fact was remarked at the rig floor. At $1000 \mathrm{~s} \mathrm{a}$ short plug of one nozzle is also detected by the system.

\subsection{Example 3: Drill Pipe Wash Out}

In Figure 14, we can observe regular drilling operations: at 11.40 a.m., at the beginning of the log section, the flow rate is in a steady state at about $2000 \mathrm{l} / \mathrm{min}$ and the SPP (in green) is at 175 bar.

All of a sudden between 11.50 a.m. and 12.00 p.m., the SPP starts to slowly decrease, all other parameters remaining steady.

Then, after nearly $2 \mathrm{~h}$ of decrease of the SPP. The drillers stops circulating at 13.30 p.m. and decides to pull out.

The data set shown in Figure 15, played back on the GetSMART, shows the various following curves.

At 11.52 a.m., a slow deviation is observed on the SPP curve as detected by symptom 1 . This is the blue curve on the left track. symptom starts to increase and at 11.58 a.m., the washout alarm is raised at $50 \%$.

At 12.30 p.m., the ratio between SPP and the theoretical pressure (symptom 2) becomes such that the alarm is raised at $70 \%$.

At 13.20 and 13.30 p.m., the rpm oscillation is observed in the SPP signal (symptom 3) when releasing the weight, indicating an eccentric leak in the drill pipe. The alarm goes up to $90 \%$.

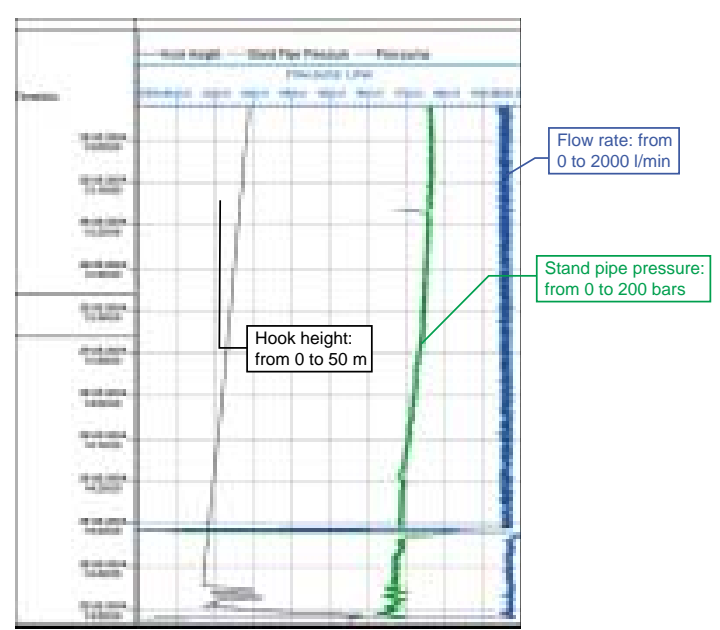

Figure 14

Display of a drill pipe wash out occurring at the well site.

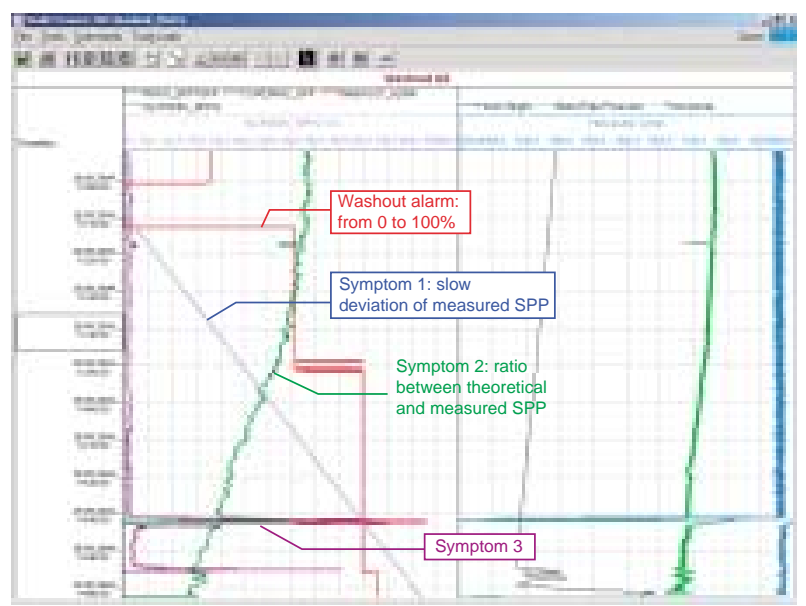

Figure 15

GetSMART parameters computed during the washout. 


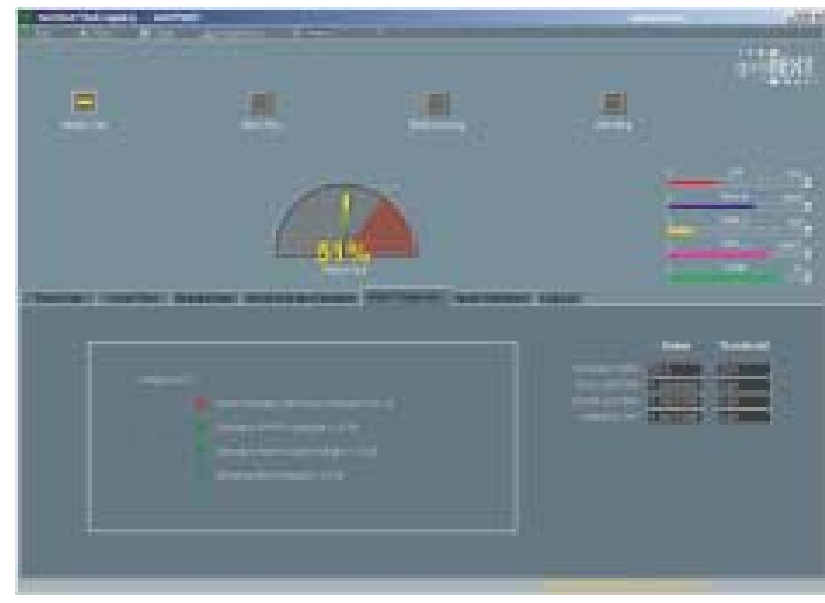

Figure 16

GetSMART monitoring screen displaying the washout alarm at $51 \%$ : orange alarm.

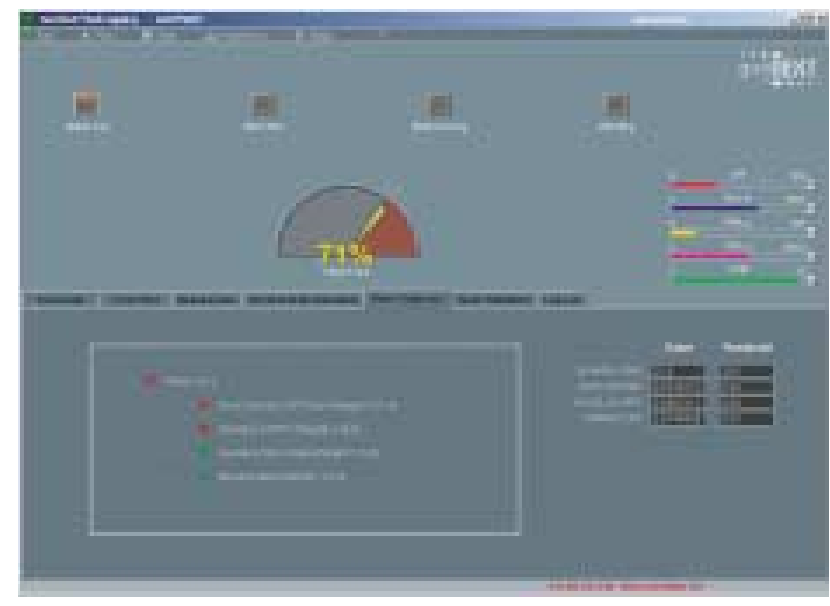

Figure 17

GetSMART monitoring screen showing the two symptoms in red and the alarm at $71 \%$ : red alarm.
This example perfectly shows that:

- A slight decrease of the SPP is immediately observed.

- As long as the SPP does not come back to its initial value, the symptom keeps on increasing, finally raising the alarm at $51 \%$ (Fig. 16).

- As soon as another element comes to confirm the diagnosis, the probability of having the problem is increased up to $70 \%$. That is the case when the difference between the measured value and its model rises above a defined threshold (Fig. 17).

- Any other additional observations/symptoms in favor of the washout give higher warning

In this case, the presence of GetSMART at the rig site would have allowed the drillers to be warned after $5 \mathrm{~min}$ (orange light at $50 \%$ ) and the diagnosis would have been confirmed after $30 \mathrm{~min}$ (red light at 70\%).

\section{CONCLUSION}

Proposed as the advanced real-time module of the new Geoservices geoNEXT ${ }^{\mathrm{TM}}$ system, GetSMART automatically warns the driller in due time of abnormal situations. This software is based on a diagnosis trees system, developed by IFP and with the help of accurate model running in real-time. With this methodology, the phenomena are analyzed and the system generates alarms for the emergence of the different malfunctions. It allows different kinds of information to be processed such as measurements while drilling or model outputs.

Some examples of real-time detection of abnormal situations have been presented. They show that the malfunctions are detected much earlier with the GetSMART system compared to the driller alone in front of his dials.

Today, GetSMART is dedicated to abnormal vibration and main hydraulic malfunction detection. Wellbore stability, which is an other major problem encountered while drilling, is studied to be soon implemented in the system.

\section{ACKNOWLEDGEMENTS}

We thank all the team of TRAFOR for giving us measurements of very high quality, Sylvie Cauvin (IFP) and Marcel Staroswiecki (LAIL, Lille, France) for their advices during the project development.

\section{REFERENCES}

1 Lutz, J., Raynaud, M., Gstalder, S., Quichaud, C., Raynal, J. and Muckleroy, J.A. (1972) Instantaneous Logging Based on Dynamic Theory of Drilling. Journal of Petroleum Technology, June, Paper 3604.

2 Besaisow, A.A., Yan, Y.M. and Schuh, F.J. (1985) Development of a Surface Drill String Vibration Measurements System. SPE 14327, September.

3 Gomel, M., Mabile, C., Perreau, P.J. and Rey-Fabret, I. (1999) Early Detection of Drill String Vibrations Based Solely on Surface Measurements, OMC.

4 Nguyen, J.P. (1993) Le forage, Éditions Technip, Paris.

5 Pavone, D.R. and Desplans, J.P. (1994) Application of High Sampling Rate Downhole Measurements for Analysis and Cure of Stick Slip in Drilling. ATCE, New Orleans, 25-28 September.

6 Rey-Fabret, I., Mabile, C. and Oudin, N. (1997) Detecting Whirling Behaviour of the Drill String from Surface Measurements. ATCE, San Antonio, 5-8 October. 
7 Mabile, C., Desplans, J.P. and Pavone, D. (1996) A New Way of Using Surface Measurements to Detect Down Hole Vibrations, SPE 36883, October.

8 Calvelo Aros, D. (1999) Apprentissage de modèles de la dynamique pour l'aide à la décision en monitorage clinique. Thèse de doctorat de l'UST de Lille, spécialité Automatique et Informatique.

9 Cauvin, S., Celse, B., Heim, B., Gentil, S. and TravéMassuyès, L. (2004) Model Based Diagnosis Module for a FCC Pilot Plant. ERTC-Computing, London, UK, May 1719.

10 Cauvin, S. and Celse, B. (2004) CHEM: Advanced Decision Support Systems for Chemical/Petrochemical Process Industries, ESCAPE-14, Lisbon, May 17-19.
11 Staroswiecki, M. (2004) Structural Analysis for Fault Detection and Isolation and for Fault Tolerant Control, in Fault Diagnosis and Fault Tolerant Control, edited by Frank, P.M. and Blanke, M. In: Encyclopedia of Life Support Systems (EOLSS), developed under the auspices of the UNESCO, Eolss Publishers, Oxford, UK, http://www.eolss.net

12 Staroswiecki, M. (2003) Fault Detection and Isolation and Fault Tolerant Estimation Design Using Structural Analysis. Plenary Lecture, 6th Polish National Science and Technology Conference: Diagnostics of Industrial Processes, Wladislawowo (PL), 15-17 September.

Final manuscript received in June 2004 